\title{
A Literature Evaluation of the Energy Efficiency of Leadership in Energy and Environmental Design (LEED) -Certified Buildings
}

\author{
Mehdi S. Kaddory Al-Zubaidy* \\ Faculty of Architecture and Environmental Design, (IIUM), Gombak, Malaysia \\ *Corresponding author: mkaddory@yahoo.com
}

Received December 22, 2014; Revised January 05, 2015; Accepted January 08, 2015

\begin{abstract}
The Leadership in Energy and Environmental Design offers a means of certifying buildings that ensure environmental sustainability. Among the key areas evaluated for the certification is the energy efficiency of the design. Most of the studies selected showed that LEED certified buildings registered energy efficiency benefits. However, a few articles challenged these findings, citing that some LEED certified buildings did not show improvement in energy efficiency compared to non-LEED certified buildings. The disparity in study findings relates to the research design of the documents studied, the design-orientation of the LEED system, differences in occupancy numbers and building energy uses and the disparity in construction periods for the buildings under study.
\end{abstract}

Keywords: Leadership in Energy and Environmental Design (LEED), LEED certified building, energy efficiency, USGBC, CBECS

Cite This Article: Mehdi S. Kaddory Al-Zubaidy, "A Literature Evaluation of the Energy Efficiency of Leadership in Energy and Environmental Design (LEED) -Certified Buildings.” American Journal of Civil Engineering and Architecture, vol. 3, no. 1 (2015): 1-7. doi: 10.12691/ajcea-3-1-1.

\section{Introduction}

Environmental concerns focusing on environmental sustainability, reduced pollution and 'green' aspects has become a central feature of modern day building designs. Human factors are the greatest contributor to aspects such as global warming [1]. Therefore, key measures are currently being employed to curb the increasing rate of global warming and ensure environmental sustainability. Among these measures is green design of buildings. This is in line with the idea of design that focuses on ensuring '... that it meets the needs of the present without compromising the ability of future generations to meet their own needs' [2]. The construction process often has adverse effects on the environment in all process including extraction, processing and material transport, and the eventual operation of the finalized facility [3].

One of the measures that ensure this is the Leadership in Energy and Environmental Design (LEED) framework. This framework focuses on five key design areas that are evaluated in the building design process. These are sustainable site development, materials selection, water savings and indoor environmental quality and energy efficiency [4]. These criteria have received their fair share of criticism, especially on the actual measurement system and its effectiveness [5,6,7]. A LEED certified building offers, lower costs of operating, happier and healthier occupants and higher lease rates for the building owners [8]. The maintenance and operations phase of any building constitutes over $80 \%$ of a building's total energy consumption [9]. Therefore, the design process should cater for this concern in ensuring sustainable building development.

However, it appears there has been no comprehensive review of literature regarding the energy efficiency of LEED certified buildings. This study undertakes on a literature evaluation of the energy efficiency of such buildings. It embarks on a methodology that seeks to focus only on the actual energy efficiency measures of LEED certified buildings with a view of determining whether the certification achieves its purpose or not. The results of this study will be of crucial help to construction industry experts such as architects and engineers. Additionally, the US Green Building Council (USGBC) will find essential information that may lead to the modification or enhancement of the existing LEED certification categories.

\section{Study Objective}

The main objective of this study is to perform a literature analysis to establish whether LEED-Certified buildings are energy efficient or not. The study undertakes on an evaluation of documented evidence from electronic databases as well as other online sources that suggest whether LEED-Certified buildings are energy efficient or not. The findings of this research are essential in determining the relevance of the LEED certification profile. Additionally, they provide crucial insight into 
defining whether newer systems of building evaluation criteria need to be developed or added into the LEED framework.

\section{Study Background}

The LEED certification criteria have undergone various development phases to its current form. Its earliest model was version 1.0 of the LEED Green Building Rating System. This pilot program focused on developing a system through which the building and construction industry would rely on creating sustainable structures. Through a commissioning and evaluation system, the USGBC awarded building designs with credits for achieving design measures that incorporated aspects such as energy efficiency, material use, water, indoor environmental quality (IEQ) and sustainable design [10]. The USGBC designed the system such that a building can be classified in the Platinum, Gold, Silver or Bronze category [4]. The rating system was reviewed to a higher version 2.0 due to the industry feedback on the pilot program. In the newer version, the Bronze category was replaced with a Certified Level. Additionally, credits related to water were increased to 5 of the 69 total points in relation to the Energy Policy Act 1992 baseline [10].
Energy related credits were additionally increased to 17 10 of which relate to energy efficiency.

Most of these revisions were in line with ensuring regulatory compliance. Apart from the Energy Policy Act, the American Society of Heating, Refrigerating and Air Conditioning Engineers (ASHRAE) standards influenced the increase in the number of energy credits. The ASHRAE standards require that the designers provide a simulation that captures the entire building's energy efficiency [11]. The LEED certification criteria have undergone continuous change since their early inception. However, the focus of the current study will be an evaluation of the energy efficiency of buildings that have passed the LEED Green Building Rating SystemTM version 2.0 criteria. Version 2.1 contained only minor changes to the original system keeping the same technical evaluation standards. Table 1 shows the main point breakdown for the version, which remained the same as the earlier one (2.0).

Table 1. Points required per level (version 2.0 and 2.1 of LEED)

\begin{tabular}{|l|c|c|c|c|}
\hline & Certified & Silver & Gold & Platinum \\
\hline Minimum & 26 & 33 & 39 & 52 \\
\hline Maximum & 32 & 38 & 51 & 69 \\
\hline
\end{tabular}

Table 2 details the key areas involved in the evaluation of energy efficiency. These are essential in the definition of 'energy efficiency' for the current study.

Table 2. Energy Efficiency credits (LEED version 2.1) [12]

\begin{tabular}{|l|l|l|}
\hline Description & Credits & Details \\
\hline Basic building systems commissioning & Prerequisite & The design ensures that basic building systems operate as per design intention \\
\hline Energy performance (minimum) & Prerequisite & $\begin{array}{l}\text { Building design complies with ASHRAE/IESNA standard 90.1-1999 or the local } \\
\text { building codes }\end{array}$ \\
\hline $\begin{array}{l}\text { The reduction of CFC in Air conditioning } \\
\text { Optimization of energy performance }\end{array}$ & 10 & Prerequisite \\
\hline Renewable energy resources & 3 & $\begin{array}{l}\text { Reduction of energy requirements for the building below regulation minimum. 1 } \\
\text { credit for proven 15\% better performance, another credit attached to each } \\
\text { subsequent 5\% improvement to the credit maximum of 10 }\end{array}$ \\
\hline Additional commissioning & 1 & $\begin{array}{l}\text { On site renewable energy sources supply 5\% of the energy cost (1 credit). Another } \\
\text { credit for 10\% and a final credit for 20\% }\end{array}$ \\
\hline Protection of the ozone layer & 1 & $\begin{array}{l}\text { Extends beyond the basic commissioning indicated above } \\
\text { and HCFCs }\end{array}$ \\
\hline $\begin{array}{l}\text { Measurement and verification of energy and } \\
\text { water use over time }\end{array}$ & 1 & $\begin{array}{l}\text { Continuous measurement and verification that optimizes water and energy use over } \\
\text { time }\end{array}$ \\
\hline Inclusion of green power sources & 1 & $\begin{array}{l}\text { Ensuring that at least 50\% of the building's electricity is from a renewable energy } \\
\text { source }\end{array}$ \\
\hline Optional energy credits (Total) & 17 & \\
\hline
\end{tabular}

Although the USGBC released a newer rating system in 2005, the focus of the current study will be on documentary evidence of energy efficiency of LEED certified buildings for the period between 2002 and 2013. This will ensure that buildings based on the earlier system are not left out of the current study. Other authors have found that ensuring improved energy efficiency does not necessarily correspond to optimal design [13]. Stegal (2004) also shows that some buildings without LEED certification enjoy higher utility efficiencies compared to LEED certified buildings [14]. Tuhus (2010) also made a point of determining that indoor air quality is of fundamental importance apart from the energy efficiency of the building [15]. Therefore, the design process should not focus on energy efficiency, ignoring air quality and other pollution considerations. However, LEED remains the most applied building rating systems.

Fowler and Rauch (2006) of the Pacific Northwest National Laboratory (PNNL) evaluated and advocated for the superiority of the LEED system to other rating systems [16]. They determined that it was the most favourable in ensuring federal compliance. Their study focused on five different rating systems. These were Building Research Establishment's Environmental Assessment Method (BREAM), Comprehensive Assessment System for Building Environmental Efficiency (CASBEE), Green Globes $^{\text {TM }}$, GB Tool and LEED. Although the current LEED system used a 100-point basis, the percentage weight associated with each criterion is still the same. LEED remains the dominant building evaluation system for US designers with other numerous developers embracing it worldwide [17]. LEED assessors are competent experts who pass a professional examination that ensures their authenticity. LEED evaluation is the most widely used system of evaluating sustainable building designs in the world [16]. The current study focuses on performing a review of the literature detailing the energy efficiency of LEED certified buildings. 


\section{Study Method}

This research undertook on a documentary analysis of all evidence that relates to the application of the LEED building certification criteria with a view of determining their energy efficiency. The following sections outline the details of the applied methodology.

\subsection{Sources of Information}

It was necessary to define 'energy efficiency' in carrying out this research. Additionally, the research had to be selective on the publications that were to be included in the analysis of evidence showing the existence or lack of energy efficiency of LEED Certified buildings. The determination of the selection criteria involved in this study posed a major challenge mainly due to the chosen building design terminologies and definitions. Additionally, the applied methodology focused on all indices of the LEED certification criteria previously outlined in earlier section. Therefore, the research design focused on a broad analysis of the available peer reviewed publications as well as the US Green Building Council (USGBC) website (which introduced the Leadership in Energy and Environmental Design certification program). The search terms involved in the current study, the inclusion and exclusion criteria (for the documentary data) are outlined in the following sections.

\subsection{Search Terms and Delimiting}

In avoiding negative effects on the feasibility of this research process, the study settled on parameter definitions that ensured the research was time bound [18]. Therefore, not every document that had a minute relation to the current discussion was reviewed. Only those that related to the primary concept of the study were reviewed and included in the study. Additionally, due to the varied meanings of 'energy efficiency' across various technical fields, several Boolean operators were included in the search criteria. The main searches terms involved in this study are those included in the keyword section and were combined in Boolean fashion. The key words were 'energy efficiency', 'LEED', 'certif*, 'building' and 'evaluation'. The main electronic databases from which research data were sourced for the current study included Scopus, Emerald Publishing, Ergonomics Abstracts, Web of Science, Discover and Academic Search Premier. The following combinations were helpful in obtaining source documents: 'LEED certif* AND energy efficiency' OR 'energy efficiency AND certify*' buildings.

\subsection{Selection Criteria}

Selection criteria were involved to avoid lengthy and non-objective analysis of documents obtained from the search results [19]. The study only selected articles, abstracts that satisfied the chosen exclusion and inclusion criteria for the current study. These are outlined below. The exclusion criteria focused on the study's outcome [20], which was to determine the evidence of energy efficiency in LEED certified buildings.

Furthermore, the current study is limited only to the actual energy efficiency of LEED-certified buildings. It does not evaluate aspects of the remaining four building evaluation areas in the LEED framework (sustainable site development, materials selection, water savings and indoor environmental quality) [4]. Therefore, the articles included in the study were those that focused on the actual energy efficiency measures of buildings that were successful with the LEED certification process. Additionally, the articles were in the English language and written in the period 2001-2013. This is because the current LEED criteria were initiated in 2000 [21]. These articles also had to include an energy evaluation, analysis and made conclusive comments on whether or not the buildings under the study actually recorded enhanced energy efficiency.

However, the study did not include articles that focused on measuring other segments of the LEED evaluation criteria. Additionally, articles not written in the English language were not included due to the lengthy process involved in translating them. On the other hand, articles written prior to 2000 were not included since they did not fall under the scope of the LEED framework. Only articles that described the LEED mechanisms employed in the buildings, but did not embark on the actual evaluation of the energy efficiency of such buildings did not form part of the study. Although energy efficiency is central to the current study, articles that evaluated building energy efficiency but not under the LEED certification were also not included. These exclusion criteria narrowed down the research process in ensuring relevance to the research problem [22].

\section{Findings}

A study by Turner (2006) assessed a sample that consisted of 11 buildings all from Cascadia, US in evaluating their post-occupancy energy performance [23]. Like most of the studies on energy efficiency, the author compared the measured utility energy usage to the three energy metrics. These were average energy used by the commercial building stock, energy usage as compared to the code-compliant baseline and the designed energy use. In the study, all sampled buildings had a better energy performance than their baseline, six of which performed better that the designed energy use and only two better than the average commercial building stock [23]. However, the exercise might have been subject to a few flaws since the variables differed slightly from those of baseline models as well as the fact that operational optimization was still under progress for some of the buildings. On the other hand, Diamond et al (2006) performed a study on a wider sample that included 21 LEED certified buildings [24]. The actual energy consumption measure was performed using utility billing data. However, the baseline building requirement and the modeled energy consumption data were obtained from the documentation for LEED certification. The results of this study proved that 18 of the buildings that had simulated building design (in line with ASHRAE requirements) registered only $1 \%$ reduction compared to the modeled energy use predictions. This was $27 \%$ below the baseline requirements. The study was subject to various discrepancies such as the large variability (a standard deviation of 46\%) where other buildings performed much better than others. This study also showed that the certified energy credits did not show any correlation with the actual energy use (measured per floor 
area). Therefore, the study concluded that a different, more comprehensive study, be performed that incorporated the actual energy versus modeled energy use data.

Apart from Turner (2006) and Diamond et al (2006), Torcellini et al (2004) determined the energy use of six green buildings that included the monitoring of energy flows, lighting loads and plug HVAC loads for a one-year period [25]. This detailed study incorporated data logging every 15 minutes for the calibration of simulation models. However, the results showed that the buildings' energy performance was worse than predicted, although significant energy savings occurred. The authors attributed the discrepancy to increased numbers of occupants that extended over the expected occupancy. They further determined that the building's hours of operation as well as space temperatures were different from the initial building design. These three studies prove that LEED certification led to significant reduction in energy consumption of buildings through the design process. Fowler \& Rauch (2008) that covered energy performance for 12 government buildings proved that energy consumption was $25 \%-30 \%$ lower than the average of most commercial building stock [16]. The buildings in the study were designed with LEED certification in mind. The authors additionally performed a non-detailed statistical analysis that suggested the existence of a relationship between the LEED energy credits and the Energy Star score (for actual energy use). The main limitation to the study resulted from the choice of the study sample since the federal government owned all the buildings under study [16]. Baylon \& Storm (2008) determined the mean energy use per floor for LEED certified commercial buildings in the Pacific Northwest in comparison to non-LEED certified buildings [26]. The study showed that the certified buildings consumed $10 \%$ less energy - a small improvement that was attributed to the high building energy standards employed in the region. The small sample size chosen in this study was also part of the limitations noted by the authors.

Turner \& Frankel (2008) performed a study on 121 LEED certified buildings, perhaps the most comprehensive study, which included results from a one-year period of measured energy usage [27]. The study proved that the median energy use intensity (EUI) for the LEED certified buildings was $32 \%$ lower than that of the mean EUI registered in the Commercial Building Energy Consumption Survey (CBECS) 2003 database. The median energy saving for the LEED buildings was 28\%, 3 points higher than the predicted 25\% energy savings. Although this study utilized a larger sample, its main limitation was that no statistical analyses were involved. The results heavily depended on average values. Additionally, the large variability of the study showed that the average measures might have been flawed. The choice of comparing median to mean values showed inconsistency in central tendency comparisons. However, this study was essential in the creation of descriptive data for LEED certified buildings that included a large sample. Newsham et al (2009) provided a supplemental analysis of the descriptive results of Turner \& Frankel (2008) to provide a firmer statistical backing [12]. The statistical analysis proved that the LEED buildings showed 18\%-39\% reduction in energy use. However, 28\%-35\% of LEED buildings showed more energy use per floor area compared to buildings in the
CBECS database. There was no evidence of statistical relationships between the LEED certification level and actual energy savings. This was possibly attributed to the commissioning, measurement and verification process. The 28\%-35\% of LEED buildings that did not register improved energy performance implies that building owners fail to realize expected gains from the LEED certification program. The study concludes that the results pose challenges on the credibility of green rating systems employed in the world [12].

Scofield (2009) performed further research on the dataset utilized by Turner and Frankel (2008) and Newsham et al (2009) and determined no energy savings for the study sample. The study focused on the source energy (consisting of on-site energy use as well as the associated off-site losses in relation to the generation and distribution) [28]. A study by Menassa et al (2012) shows that 7 of the 11 sampled LEED certified buildings had electrical energy savings when compared to non-LEED buildings [29]. Of these, only 2 registered over 30\% energy savings per year, while 5 showed less than $15 \%$ in energy savings. This was despite the knowledge that the buildings scored between 2 and 14 credits of the energy saving criteria. Menassa et al (2012) also proved that the LEED certified buildings in the study showed little or no improvement in the energy saving ability compared to CBECS buildings. Only 3 of the 11 studied facilities showed improved energy efficiency gains. This study proved that LEED certification is not sufficient on its own to guarantee building energy efficiency.

The energy efficiency of LEED certified buildings has also come under significant legal scrutiny, particularly in the June 2010 case where Henry Gifford claimed that the LEED system is misleading [30]. Gifford, president of Gifford Fuel Saving and an expert in energy efficiency claimed that the LEED system is based on anticipated consumption levels and not actual energy usage levels. He charged that although the system does not have a proven measurement system, it posed the threat of obscuring proven measurement systems such as the CBECS standard. Gifford's challenge stems from the Turner \& Frankel (2008) study that showed increased energy efficiencies for LEED certified buildings. The main concerns relate to the research design. Although 252 building owners responded, only 121 were included in the final study. Gifford claimed that the USGBC knowingly relied on a skewed sample. Additionally, the claims suggested that the inclusion of LEED certified buildings ignored the negative implication of vested interests since such buildings would want to boost their commercial value due to the paid for LEED registration. The comparison of median and mean values was a point of contention that allowed LEED buildings to seem more efficient compared to CBECS accredited buildings. The use of median values ignores extreme data sets while mean values include all data [31]. Other authors also offer stiff oppositions to the LEED criteria [32,33]. Therefore, these two cannot be effectively compared without the inclusion of standard deviation measures.

\section{Discussion}

Several studies prove the energy efficiency of LEED certified buildings [16,23,24,25,26,27]. Additional studies 
query the efficiency of such buildings [28-30]. Several factors led to this disparity in results. The sub-sections below outline these factors.

\subsection{Research Design Factors}

The differences in the research designs involved in the review caused the mentioned disparities that showed energy efficiency of LEED certified buildings in some cases and lack of in other cases. Bias limitation and enhancement of research reliability are central to the research design process [34]. The concerns raised by Gifford raised valid concerns on sample selection in the NHI survey. The research design, in this case, showed research bias in the selection process. Although this may not have been voluntary bias since LEED certified buildings had to be included in the study, it nevertheless introduced bias. This is because LEED certified buildings pay for this certification and may want to yield financial gains in terms of higher lease prices. On the other hand, the choice of comparing median values of the LEED sample to the mean values of the national stock sample (CBECS) in the Turner \& Frankel (2008) study is subject to statistical questions. This is because the median value is less sensitive to the values in the data set that are extreme [35]. Energy efficiency analyses should compare equivalent statistical measures. Additionally, the sample selection should be devoid of bias.

\subsection{The LEED Certification Program Design}

Although the LEED certification criteria are embraced worldwide, it is subject to various limitations that lead to the non-realization of energy efficiency goals. The system has several scoring points, which can be achieved without necessarily meeting all 17 of the energy points. For instance, more than $90 \%$ of the certified buildings get the accredited certification due to the use of adhesives; indoor paints and flooring that emit fewer contaminants thus ensuring occupant health [36]. These considerations do not contribute directly to energy efficiency. The design ensures that an office building earns the minimum 32 points needed for certified level. Rob Watson, who led the writing of the early version of the LEED criteria, suggests this by claiming 'we wanted people who were 6 or 7 points away to see that... LEED was accessible' [36]. This claim defeats the energy efficiency purpose. Therefore, the USGBC can only achieve improved energy gains if only it ensures that it is mandatory for new buildings to achieve at least three quarters of the points needed for energy credits. Additionally, future research on the energy efficiency of LEED certified buildings should cater for buildings that have earned more than 15 of the total 17 points in the energy credits section. This would ensure more focus on the energy efficiency criteria.

\subsection{Differences in Time Criteria}

The studies evaluating the energy efficiency of LEED certified buildings compared their energy measurement findings to data from the national stock (CBECS). The CBECS data normally groups, buildings by decades. However, some of the design studies included in this analysis such as Turner and Frankel (2008) captured data that was only a few years old (less than a decade). This leads to the conclusion that the choice of using data from a few years does not establish a reliable trend for comparing to the CBECS database [37].Therefore, the comparison criteria should have had a keen focus on choosing which LEED certified buildings to compare against non-LEED certified structures.

\subsection{Differences in Building Occupancy Characteristics}

An increase in the number of building tenants might denote an increase in the energy consumption. Although the design process caters for a set number of occupants, the actual number of occupants changes once the building becomes operational. This explains why some of the country's oldest buildings are more energy efficient compared to LEED certified buildings. The World Trade Centre boasts of a LEED-Gold rating, yet it has equivalent energy efficiency to the Chrysler building (a 1930 construction) [38]. This can be attributed to the energy consumption of tenants. Newer buildings tend to host electronic data centers that consume much more energy. However, non-profit firms tend to consume less in terms of energy for data storage and processing purposes.

\subsection{Design versus Performance Criteria}

The LEED criteria measure the design processes of a building. They are predictive. However, these processes changes soon after occupancy. A uniform mode of comparison is needed so that LEED energy efficiency measures focus on both design and performance measures. This would then lead to certification only after a performance based analysis. Predictions may fail to incorporate the increase in tenancy as well as differences in energy use by the occupants. Additionally, it is suggested that the criteria can be gamed for certification [39]. There is compelling evidence showing how one can achieve the LEED building certification without ensuring maximal energy efficiency [40]. The LEED tool is a design-oriented platform in as much as it requires an annual report on the water and energy use. It does not offer performance incentives by performing a follow through on what the design process promised. This explains the differences in the research study findings outlined in the results.

\subsection{Limitations}

The initial search strategy included numerous articles, which were either excluded or included depending on the selection criteria involved in the study - a potential source for research bias. Additionally, the research did not focus on a statistical analysis of the documented sources, only detailing the results obtained from the sources. This offers no statistical contribution to the growing body of literature on the energy efficiency of LEED certified buildings. However, the chosen structure ensures a consolidation of facts and statistics pertaining to the research topic.

\section{Conclusion}

The purpose of this study was to perform a literature evaluation of the energy efficiency of LEED-Certified 
Buildings. Most research studies proved the improved energy efficiencies associated with a LEED certified building [12,16,23,24,25,26,27]. However, a few studies showed that some LEED buildings did not achieve significant energy efficiencies [28,29,30,32,33,41]. Scofield (2009) challenged the methodology settled upon by Turner \& Frankel (2008) as well as Newsham et al (2009). The study found that LEED certified buildings did not achieve purported energy efficiencies [28]. These disparities in the results are attributable to various factors such as the chosen research design in determining energy efficiency, the design-orientation of the LEED criteria, the LEED certification design, differences in time of construction of the buildings and unpredicted occupancy numbers and energy uses. The results of this study will be of crucial help to construction industry experts such as architects and engineers. Additionally, the US Green Building Council (USGBC) will find essential information that may lead to the modification or enhancement of the existing LEED certification categories. Future research should focus on comparing buildings that were built in the same period. Additionally, the operational occupancy numbers and energy use should correspond to the design specifications leading to accurate analyses. On the other hand, the USGBC should consider that the certification criteria incorporate a mandatory threshold that requires satisfaction of over 15 points of the energy efficiency criterion. However, since the implementation of this requirement will be fraught with challenges, future research on energy efficiency should focus on buildings that meet this threshold to ensure objectivity.

\section{References}

[1] Purdey, S. (2012). The Normative Root of the Climate Change Problem. Ethics and the Environment, 17 (2), pp. 75-96.

[2] Brundtland, G. (1987). Report of the World Commission on Environment and Development: Our Common Future. United Nations General Assembly document A/42/427.

[3] Zou, W. \& Couani, P. (2012). Managing Risks in Green Building Supply Chain. Architectural engineering and Design Management, 8, pp. 143-158.

[4] USGBC (2013). LEEDS. Retrieved 21June 2013 from http://www.usgbc.org/leed.

[5] Melinda, T. (2010). The Question of LEED: Why the Country's Leading Green Building Certification may be Inherently Flawed. The Envirnomental Magazine, 21 (6), pp. 15-19.

[6] Nadine, M. (2009). Building Rating System Requirement Raises Concerns. Engineering News Record, 263 (2), pp. 12-13.

[7] Industrial Engineer (2009). Freshness Counts, Too. IE, 44(12), pp. 14.

[8] Brown, R. (2010). LEEDing to Better Buildings. USA Today Magazine, 139 (2786), p 61.

[9] UNEP (2007). Buildings can play key role in combating climate change. UNEP News Centre. Retrieved on 17 June 2013 from http://www.unep.org/Documents.Multilingual/Default.asp?Docum entID $=502 \&$ ArticleID $=5545 \&=$ en .

[10] Nyikos, D., Thai, A., Hicks, M \& Leach, S. (2012). To LEED or Not to LEED: Analysis of Cost Premiums Associated With Sustainable Facility Design. Engineering Management Journal, 24 (4), pp. 50-62.

[11] Cho, H., Gowri, K. \& Liu, B., 2010. Modelling of Air Infiltration through Door Openings. Washington: US Department of Energy.

[12] Newsham, R., Mancini, S. \& Birt, B. (2009). Do LEED-certified buildings save energy? Yes, but... Energy and Buildings, 41 98), pp. 897-905.

[13] Hedge, A., Rollings, K., \& Robinson, J. (2010). Green Ergonomics: Advocating for the Human Element in Buildings,
Proceedings of the Human Factors and Ergonomics Society 54th Annual Meeting, pp. 693-697.

[14] Stegal, N. (2004). Cost Implications of LEED Silver Certification for New House Residence Hall at Carnegie Mellon University. Senior Honors Research Project, Carnegie Institute of Technology. Retrieved 18 June 2013 from http://www.cmu.edu/greenpractices/greeningthe-campus/greenbuildings/newhouse_report.pdf.

[15] Tuhus, M. (2010). The Question of LEED: Why the country's leading green building certification may be inherently flawed. The Environmental Magazine, 21 (6), pp. 15-19.

[16] Fowler, M., \& Rauch, M. (2006). Sustainable Building Rating Systems Summary. Pacific Northwest National Laboratory Report 15858, Retrieved 20 June 2013 from

http://wbdg.org/ccb/GSAMAN/sustainable_bldg_rating_systems.p df.

[17] Johansson, O. (2011). The spatial diffusion of green building technologies: The case of Leadership in Energy and Environmental Design (LEED ) in the United States. International Journal of Technology Management \& Sustainable Development, 10 (3), pp. 251-266.

[18] DePoy E, Gitlin N. (1993). Introduction to research: multiple strategies for health and human services. St. Louis: Mosby-Year Book.

[19] Mulrow, C. and Cook, D. (1998). Systematic Reviews: Synthesis of Best Evidence for Health Care Decisions. Race: ACP Press.

[20] Tyrer, P. and Freeman, C. (2006). Research Methods in Psychiatry. London: The Royal College of Psychiatrists.

[21] AccessPoint (2013). History of LEED. Retrieved 20 June 2013 from

http://www.businessrecovery.ws/leed-certification/history-of-leed.

[22] Oxman D. (1994). Systematic reviews: checklists for review articles. BMJ, 309, pp. 648-51.

[23] Turner, C. (2006). LEED building performance in the Cascadia Region: A post occupancy evaluation report. Retrieved 18 June 2013 from

https://www.usgbc.org/chapters/cascadia/docs/pdf/POE_REPORT _2006.pdf.

[24] Diamond, R., Optiz, M., Hicks, T., Vonneida, B. \& Herrera, S. (2006). Evaluating the energy performance of the first generation of LEED-certified commercial buildings. ACEEE Summer Study on Energy Efficiency in Buildings, pp. 3/41-3/52.

[25] Torcellini, P., Deru, M., Griffith, B., Long, N., Pless, S. \& Judkoff, R. (2004). Lessons learned from the field evaluation of six highperformance buildings. ACEEE Summer Study on Energy Efficiency of Buildings, pp. 3-325 to 3-337.

[26] Baylon, D.; Storm, P. (2008). Comparison of commercial LEED buildings and non-LEED buildings within the 2002-2004 Pacific Northwest commercial building stock. ACEEE Summer Study on Energy Efficiency of Buildings, pp. 4/1 to 4/12.

[27] Turner, C. \& Frankel, M. (2008). Energy performance of LEED for New Construction Buildings, Final Report. Washington: US Green Building Council.

[28] Scofield, J. (2009). Do LEED-certified buildings save energy? Not really... Energy Build, 41 (12), pp. 897-905.

[29] Menassa, C., Managasarian, S., Asmar, M. \& Kirar, C. (2012). Energy Consumption Evaluation of US Navy LEED-Certified Buildings. Journal of Performance of Constructed Facilities, 26 (1), pp. 46-53.

[30] Kamal, S. Lawsuit Contrasts LEED Certification and Energy Efficiency. Retrieved 20 June 2013 from www.greenbuildingnews.com/articles/2011/02/4/lawsuitecontrasts-leed-certification-and-energy-efficiency.

[31] Osborn, C. (2006). Statistical Applications for Health Information Management. Sudbury: Jones and Bartlett Publishers, Inc.

[32] Gershman, J. (2009). Fake Green Labels, Buildings Don’t Save Energy. The New York Post, September 21 2009. Retrieved 19 June 2013 from http://www.nypost.com/p/news/opinion/opedcolumnists/fake_gree n_labels_aU9PWSSD4p71LigLp0z4eO.

[33] Dunn, S., and Makela, E. (2008). Going beyond code: A guide to creating energy efficient and sustainable buildings in the southwest. Boulder: Southwest Energy Efficiency Project.

[34] Khan, K. S., Kunz, R., Kleijnen, J., \& Antes, G. (2003). Systematic Reviews to Support Evidence-based Medicine: How to review and apply findings of healthcare research. London: The Royal Society of Medicine Press Ltd. 
[35] Mendenhall, W., Beaver, R. and Beaver, B. (2013). Introduction to Probability and Statistics, 14th Edition. Boston: Cengage Learning.

[36] USA Today, 2013. In U.S. Building Industry, is it too Easy to be Green? Retrieved 20 June 2013 from http://www.usatoday.com/story/news/nation/2012/10/24/greenbuilding-leed-certification/1650517/.

[37] Malin, N. (2008). Lies, Damn Lies, and... (Another Look at LEED Energy Efficiency). Retrieved 20 June 2013 from http://www2.buildinggreen.com/blogs/lies-damn-lies-and-anotherlook-leed-energy-efficiency.

[38] Sustainable Business News (2013). Why some NYC buildings are more efficient than LEED-certified ones. Retrieved 20 June 2013 from http://www.greenbiz.com/blog/2013/01/03/some-nyc-buildingsmore-efficient-leed-certified?page $=0 \% 2 \mathrm{C} 0$.

[39] Quirk, V. (2012). Where is LEED Leading Us?... And Should We Follow? Retrieved 21 June 2013 from http://www.archdaily.com/227934/where-is-leed-leading-us-andshould-we-follow.

[40] Seville, C. (2011). How to Cheat at LEED for Homes. Retrieved 21 June 2013 from http://www.greenbuildingadvisor.com/blogs/dept/green-buildingcurmudgeon/how-cheat-leed-homes.

[41] Oates, D. \& Sullivan, K. (2012). Postoccupancy Energy Consumption Survey of Arizona's LEED New Construction Population. Journal of Construction Engineering \& Management, 138 (6), pp. 742-750.

[42] Al-Zubaidy, Mehdi S. Kaddory; Omer, Spahic; Abdullah, Alias (2013), Minimizing Environmental Impact on World Heritage Sites by Exploiting Green Energy, Journal of Global Intelligence \& Policy;Fall2013, Vol. 6 Issue 11, p141Jacobs, M. \& Fernández, F. (2009), Alhambra, Frances Lincoln.

[43] Mehdi S. Kaddory Al-zubaidy. (Vol. 3 - Issue 11 (November 2014)). "Use of Novel Green Energy Design in Sustainable Buildings to Mitigate Effects of Climate Change", International Journal of Engineering Research \& Technology (IJERT). 